\title{
Pharmacopoeial Analysis of Inulin-Containing Medicinal Plant Raw Materials and Drugs
}

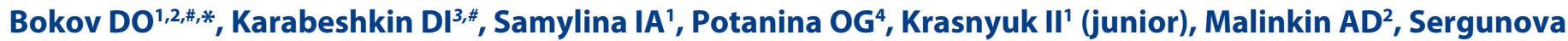 \\ EV', Kovaleva TYu' ', Bobkova NV', Antsyshkina AM', Bondar AA', Evgrafov AA', Galiakhmetova EK', Moiseev \\ DV6 ${ }^{6}$, Bessonov VV ${ }^{2}$
}

\section{Bokov DO $1,2, *, \#$, Karabeshkin $\mathrm{DI}^{3, \# \text {, Samylina IA }{ }^{1} \text {, Potanina OG }}{ }^{4}$, Krasnyuk II' (junior), Malinkin $A D^{2}$, Sergunova $E V^{1}$, Kovaleva $\mathrm{TYu}^{1}$, Bobkova NV', Antsyshkina $A M^{1}$, Bondar $A A^{1}$, Evgrafov $A A^{1}$, Galiakhmetova $\mathrm{EK}^{5}$, Moiseev DV ${ }^{6}$, Bessonov VV ${ }^{2}$}

'Institute of Pharmacy, Sechenov First Moscow State Medical University, 8 Trubetskaya St., bldg. 2, MosCow, 119991, RUSSIAN FEDERATION. 'Laboratory of Food Chemistry, Federal Research Center of Nutrition, Biotechnology and Food Safety, 2/14 Ustyinsky pr., Moscow, 109240, RUSSIAN FEDERATION.

${ }^{3}$ Normal physiology department, Northern State Medical University, 51Troitsky pr., 163000, Arkhangelsk, RUSSIAN FEDERATION.

${ }^{4}$ Pharmaceutical chemistry and pharmacognosy chair, Peoples' Friendship University of Russia (RUDN University), 6, Miklukho-Maklaya Street Moscow, 117198, RUSSIAN FEDERATION. ${ }^{5}$ Department of pharmacognosy with a course in botany and the basics of herbal medicine, Bashkir state medical University, 3, Lenina str., Ufa, 450008, RUSSIAN FEDERATION.

${ }^{6}$ Chair of Standardization of Medicines, Vitebsk State Medical University, 27, Frunze avenue Vitebsk, 210062, BELARUS.

\#Contributed equally to this work.

\section{Correspondence}

\section{Dmitry Bokov}

Institute of Pharmacy, Sechenov First Moscow State Medical University, 8 Trubetskaya St., bldg. 2, Moscow, 119991; Laboratory of Food Chemistry, Federal Research Center of Nutrition,

Biotechnology and Food Safety, 2/14

Ustyinsky pr., Moscow, 109240, RUSSIAN FEDERATION

E-mail: fmmsu@mail.ru

History

- Submission Date: 18-01-2020;

- Review completed: 30-01-2020;

- Accepted Date: 06-02-2020.

\section{DOI : 10.5530/pj.2020.12.64}

Article Available online

http://www.phcogj.com/v12/i2

\section{Copyright}

(C) 2020 Phcogj.Com. This is an openaccess article distributed under the terms of the Creative Commons Attribution 4.0 International license.

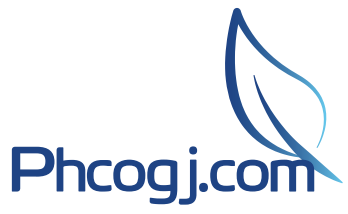

\section{ABSTRACT}

Background: Today, there are some unresolved issues and discussions concerning inulin quantitative determination in medicinal plant raw materials (MPRM). MPRM containing polyfructans or fructosans (inulin and others) are rather complex multicomponent matrixes with many interacting compounds. The article discusses the prospects for further standardization of inulin-containing pharmacopoeial MPRM that include, in addition to polysaccharides (inulin), other biologically active compounds with pharmacological activity. Materials and Methods: Different types of search tools such as Google scholar, Google, scientific literature, normative documentation of Russian Federation (State Pharmacopoeia of Russian Federation IV edition and others) electronic databases such as e-Library, Scopus, Web of Science, Pubmed had been searched and data obtained. Results: The pharmacopoeial spectrophotometric procedures of inulin determination in the Russian Federation are approved in a version that does not fully satisfy modern standardization criteria. Regulatory changes required in the near future. Conclusion: Undoubtedly, to determine inulin quantitatively, it is necessary to modify the existing spectrophotometric procedures and introduce an additional alternative, more specific HPLC-RID (or similar) ones.

Key words: Inulin quantitative determination, Polyfructans, Fructosans, HPLC-RID.

\section{INTRODUCTION}

Nowadays, such diseases as diabetes mellitus, atherosclerosis, dysbiosis, and alimentary obesity occupied a prominent position despite the significant successes of medicine and pharmacy, the improvement of living conditions and nutrition of the population. These diseases lead to disability, and, as a result, to a high mortality rate. Phytotherapy is of great importance in the prevention and comprehensive treatment of such patients. Phytotherapy has several advantages over treatment with synthetic drugs. These advantages are: high pharmacotherapeutic efficacy of herbal remedies, low toxicity or lack thereof, mild action, which determines the possibility of their long-term use without the risk of adverse reactions. ${ }^{1,2}$

Inulin and fructooligosaccharides (fructosides of various polymerization degrees) are reserve polysaccharides of some plants, actively used in both the pharmaceutical and food industries; they are utilized in the production of biologically active additives and drugs. They can positively affect the metabolism, activate the pancreas function, stabilize blood glucose levels, promote the excretion of heavy metals salts and the absorption of calcium, iron, as well as provide hypocholesterolemic, immunomodulating and prebiotic effects. Currently, interest in polysaccharides, and particular inulin, has increased significantly; whereas previously polysaccharides were mainly used as excipients in the production of various dosage forms, in recent years they have been more widely regarded as biologically active compounds (BAC). Thereby, the standardization of inulincontaining medicinal plant raw materials (MPRM) seems to be very relevant and necessary. ${ }^{3,4}$

\section{MATERIALS AND METHODS}

Different types of search tools such as Google scholar, Google, scientific literature, normative documentation of Russian Federation (State Pharmacopoeia of Russian Federation IV edition and others) electronic databases such as e-Library, Scopus, Web of Science, Pubmed had been searched and data obtained.

\section{RESULTS AND DISCUSSION}

\section{Characterization of polyfructans}

Fructooligosaccharides (FOS) (oligofructose) - a mixture of oligomers, which contain from 1 to 7 moieties of D-fructose, and as a rule, terminal $\mathrm{D}$-glucose. FOS is obtained in two ways: by splitting inulin and by enzymatic transfer of fructose to sucrose (transfructosylation). Oligofructose, like inulin, belongs to water-soluble dietary fiber and is prebiotic, and a mixture of these compounds, which is also often called fructooligosaccharides, has more effective prebiotic properties. Polyfructans (fructosans, Pfrus) are carbohydrate polymers formed by a sucrose molecule, an extended chain of fructose moieties. In nature, Pfrus are found in bacteria, fungi, and plants in which they perform various 
functions. This class of natural polysaccharides (PSh) is produced by more than $15 \%$ of plant species belonging to different families. Pfrus are most commonly found in Liliaceae, Asteraceae, Campanulaceae, and Polemoniaceae. Structurally, Pfrus are divided into three classes, which differ in the type of bond between the moieties of fructose: the inulin group (Figure 1$)-\beta$ - $(2 \rightarrow 1)$-link; levan group - $\beta$ - $(2 \rightarrow 6)$-link; graminan group $-\beta-(2 \rightarrow 1)$ and $\beta$ - $(2 \rightarrow 6)$-link. Pfrus inulin groups are used to produce several dietary supplements that can positively affect metabolism, stabilize blood glucose levels and, in connection with this, partially replace antidiabetic drugs. Inulin helps to remove heavy metal salts from the body and assimilate calcium and iron, as well as activate the pancreas and affect the carbohydrate metabolism in the liver. There is evidence of the presence of inulin probiotic and immunomodulating properties. $^{3,5}$

\section{Procedures for inulin determination}

Nowadays, there are many analytical methods for determining inulin, both as an individual pharmaceutical substance, and as part of medicinal plant materials and complex preparations. These methods include high performance liquid chromatography, high-performance anion exchange chromatography with pulsed amperometric detection, spectrophotometric and photocolorimetric determination methods. These methods are analyzed in great detail in the works ${ }^{6-9}$, so we will not dwell on their analysis here.

Most often, methods are used to determine the quantitative content of inulin in terms of the dominant product of its hydrolysis - fructose. However, the problems that arise during the determination are related to the selection of the optimal conditions for the process (temperature, time), the degree of hydrolysis, as well as the presence of by-products or low molecular weight fractions, which cause a significant error in most existing methods. An important role is played by the high cost of the reagents and equipment involved in the analysis, as well as the considerable complexity of the determination process. ${ }^{10-13}$

\section{Pharmacopoeial methods of inulin analysis in MPRM}

The spectrophotometric method is based on the Seliwanoff's reaction for free fructose (Figure 2). Fructose interacts with resorcinol in concentrated hydrochloric acid when heated; the liquid becomes red gradually. The reaction is caused by an unstable compound 5-(hydroxymethyl)furfural (HMF), forming during the oxidation of fructose. Under the influence of concentrated hydrochloric acid, the latter condenses with resorcinol, giving a colored compound. The reaction is based on the property of HMF to be formed from ketoses quite easily. ${ }^{14}$

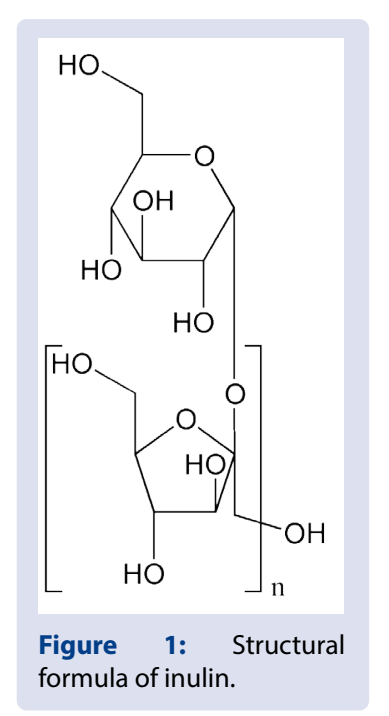

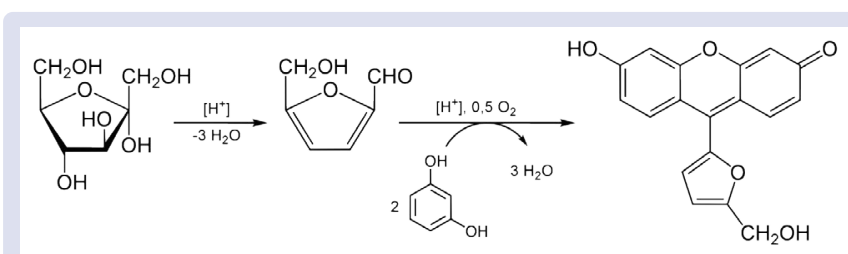

Figure 2: Seliwanoff's reaction.

In Russia, several types of plant material containing Pfrus of inulintype are official: burdock roots, elecampane rhizomes and roots, dandelion roots. Next, we discuss two pharmacopeial procedures for determining Pfrus in burdock and elecampane MPRM; only extractives are determined in dandelion MPRM. ${ }^{15}$

The structures that inulin forms (inulin clumps) are well defined by microscopic analysis (Figure 3). Dandelion root parenchyma cells are filled with colorless lumps (inulin mass forming specific bodies) and clumps (small lumps) of inulin, which dissolve easily when the slide mount is heated (cross-section of the root), and inulin is also contained in the wood parenchyma cells. Parenchymal cells of the inner part of the cortex, wood and the core rays of the burdock root contain inulin lumps (slide mount of a cross-section of the root without heating). The elecampane rhizome with roots parenchyma cortex cells contain inulin in the form of shapeless, colorless, highly refracting light lumps (the slide mount is viewed without heating).

Burdock is a herbaceous biennial plant. It is widely used in folk and official medicine; more commonly used burdock root, which has a rich chemical composition (polysaccharides, essential oils, fatty oils, tannins) and pharmacological properties. According to pharmacopeial monograph (PM) of State Pharmacopoeia of Russian Federation 2.5.0025.15 MPRM “Arctii radices - Burdock roots" are presented by collected in autumn or early spring, peeled from the remains of stems, leaves, thin roots, washed from the ground, cut into pieces and dried roots of biennial herbaceous plants of greater burdock (Arctium lappa L.), woolly burdock (Arctium tomentosum Mill.), little burdock (Arctium minus (Mill.) Bernh.) Asteraceae family (Figure 4). A decoction of the burdock roots has a diuretic, moderate choleretic and diaphoretic effects, improves mineral metabolism; it has a local anti-inflammatory and wound healing effects. ${ }^{15-23}$.

According to the PM total content of polysaccharides in terms of fructose should be at least $8 \%$ in burdock roots (whole/crushed/ powder). For analysis, the MPRM analytical sample is crushed to the size of the particles passing through a 1-mm sieve. About $1.0 \mathrm{~g}$ (accurately weighed) of the crushed MPRM is placed in a $250 \mathrm{ml}$ flask with a thin section, $60 \mathrm{ml}$ of water is added and heated on a tile for 30 minutes. The resulting extract is cooled to room temperature and filtered through a paper filter into a $200 \mathrm{ml}$ volumetric flask, avoiding the ingress of MPRM on the filter. The extraction is repeated twice more, each time using $30 \mathrm{ml}$ of water: the first time for 30 minutes, and the second for 15 minutes. ${ }^{15}$ The MPRM is transferred to a paper filter, the flask is washed, and then the residue on the filter is washed, using $10 \mathrm{ml}$ of water each time. To the resulting extract $2 \mathrm{ml}$ of $10 \%$ lead acetate solution is added, mixed and left for 10 minutes. Then $2 \mathrm{ml}$ of $5 \%$ sodium phosphate disubstituted solution is added, mixed and left for 5 minutes. Then the volume of the solution is adjusted to the mark with water and mixed. The solution is filtered through a paper filter, discarding the first 10-15 $\mathrm{ml}$ of the filtrate (solution A). $5.0 \mathrm{ml}$ of solution A is placed in a $100 \mathrm{ml}$ volumetric flask, the volume of the solution is adjusted to the mark with water and stirred (solution B). In a $25 \mathrm{ml}$ volumetric flask, $5 \mathrm{ml}$ of $0.1 \%$ resorcinol alcohol solution, $5.0 \mathrm{ml}$ of solution $\mathrm{B}$ are added, the volume is adjusted to the mark with $30 \%$ hydrochloric acid solution and stirred (solution C). In a $25 \mathrm{ml}$ volumetric flask $5 \mathrm{ml}$ of $0.1 \%$ resorcinol alcohol solution, $5 \mathrm{ml}$ of water are added, the volume is adjusted to the mark 

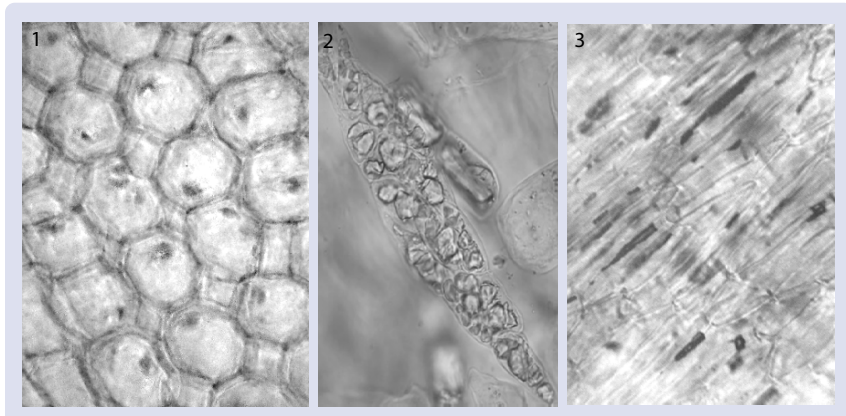

Figure 3: The fragment of a burdock root cross section slide mount: parenchyma cortex cells with inulin lumps (1). The pressed slide mount: dandelion root parenchyma cells with inulin (2), elecampane rhizome with roots parenchyma cells with inulin (3).

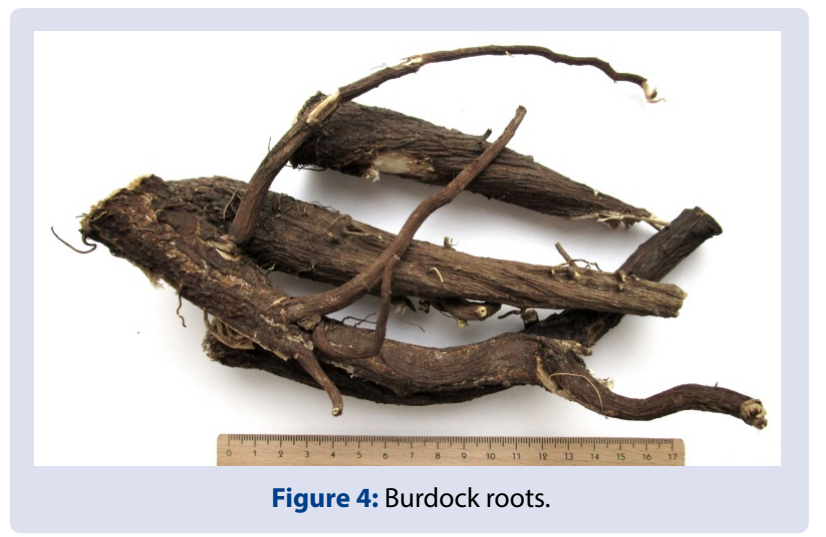

with $30 \%$ hydrochloric acid solution and stirred (reference solution). The flasks with the reference solution and solution $\mathrm{B}$ are heated in a water bath at a temperature of $80^{\circ} \mathrm{C}$ for 20 minutes, cooled; the volume of extracts in the flasks is adjusted with the same solvent to the mark. The optical density of solution B is measured on a spectrophotometer at a wavelength of $482 \mathrm{~nm}$ in a cuvette with a $10 \mathrm{~mm}$ layer thickness in comparison to the reference solution. The total polysaccharides content in terms of fructose is calculated using the specific absorption coefficient of the reaction products of fructose with resorcinol in an acidic medium, in absolutely dry MPRM (X) according to the formula:

$X=\frac{A \cdot 200 \cdot 100 \cdot 25 \cdot 100}{A_{1 \mathrm{~cm}}^{1 \%} \cdot a \cdot 5 \cdot 5 \cdot(100-W)}$

where $A_{\mathrm{o}}$ - the optical density of solution $\mathrm{B} ; A_{1 \mathrm{~cm}}^{1 \%}$ - specific absorption coefficient of the reaction products of fructose with resorcinol in an acidic medium at a wavelength of $482 \mathrm{~nm}$, equal to 298; $a$ - sample mass of MPRM, g; $W$ - moisture content in MPRM, $\% .^{15}$

Elecampane is a perennial herb with yellow flowers up to 1.5 meters high. In official medicine, rhizomes and roots are used; it contains polysaccharides (inulin), essential oils, bitter glycosides, saponins, etc. According to the PM "Elecampane rhizomes and roots - Inulae helenii rhizomata et radices", the MPRM is presented by collected in autumn, peeled from the remains of aerial parts and ground, dried rhizomes and roots of a wild-growing and cultivated perennial herbaceous plant of Elecampane (Inula helenium L.), Asteraceae family (Figure 5). The infusion of elecampane rhizomes and roots has an expectorant effect. ${ }^{15,16,24-28}$

The PM includes the section "Determination of the main groups of biologically active substances", where a qualitative reaction for inulin is presented. Orange-red coloring (inulin) should be observed when applying specific reagent to a cross-section of elecampane MPRM (whole or powder), Figure 6. It includes $0.1 \mathrm{ml}$ of $20 \%$ thymol alcohol solution and $0.05 \mathrm{ml}$ of concentrated sulfuric acid. Blue staining should not be observed (absence of starch) when applying specific reagent $(0.1$ $\mathrm{ml}$ of iodine solution) to elecampane MPRM (whole or powder).

According to the PM, the total content of fructosans and fructose in terms of inulin should be at least $25 \%$ in elecampane MPRM (whole/ crushed/powder). For analysis, an analytical sample of the MPRM is crushed to the size of the particles passing through a $1 \mathrm{~mm}$ sieve. About $1.0 \mathrm{~g}$ (accurately weighed) of the crushed material is placed in a $250 \mathrm{ml}$ flask, $60 \mathrm{ml}$ of water is added and heated in a boiling water bath for 45 minutes, then cooled at room temperature for 5 minutes. The resulting extract is filtered through cotton wool into a $200 \mathrm{ml}$ volumetric flask avoiding the ingress of MPRM on the filter. The flask is washed with $10 \mathrm{ml}$ of water and flushing water is filtered into the same volumetric flask. The extraction with water is repeated twice more (the first time it is heated for 45 minutes with $30 \mathrm{ml}$ of water, the second time - 15 minutes with $30 \mathrm{ml}$ of water), the extract is filtered into the same volumetric flask. Then the MPRM is transferred to cotton wool, the flask is washed with $10 \mathrm{ml}$ of water, flushing water is filtered through the cotton with another $10 \mathrm{ml}$ of water. Cotton wool with MPRM is squeezed. $1 \mathrm{ml}$ of $10 \%$ lead (II) acetate solution is added to the resulting flask in a volumetric flask, stirred and left for 10 minutes. Then $2 \mathrm{ml}$ of $5 \%$ disodium hydrogen phosphate anhydrous solution is added to the flask, stirred and left for 5 minutes. Then the volume of the solution in the flask is adjusted to the mark with water and mixed. The contents of the flask are filtered through a paper filter, discarding the first 10-15 $\mathrm{ml}$ of the filtrate. $2 \mathrm{ml}$ of the filtrate is placed in a $100 \mathrm{ml}$ volumetric flask, the volume of the solution is adjusted to the mark with water, and stirred (solution A of the test solution). $5 \mathrm{ml}$ of $0.1 \%$ resorcinol alcohol solution and $10 \mathrm{ml}$ of $30 \%$ hydrochloric acid are placed in each of two $50 \mathrm{ml}$ conical flasks. Then, $5 \mathrm{ml}$ of solution A of the test solution is
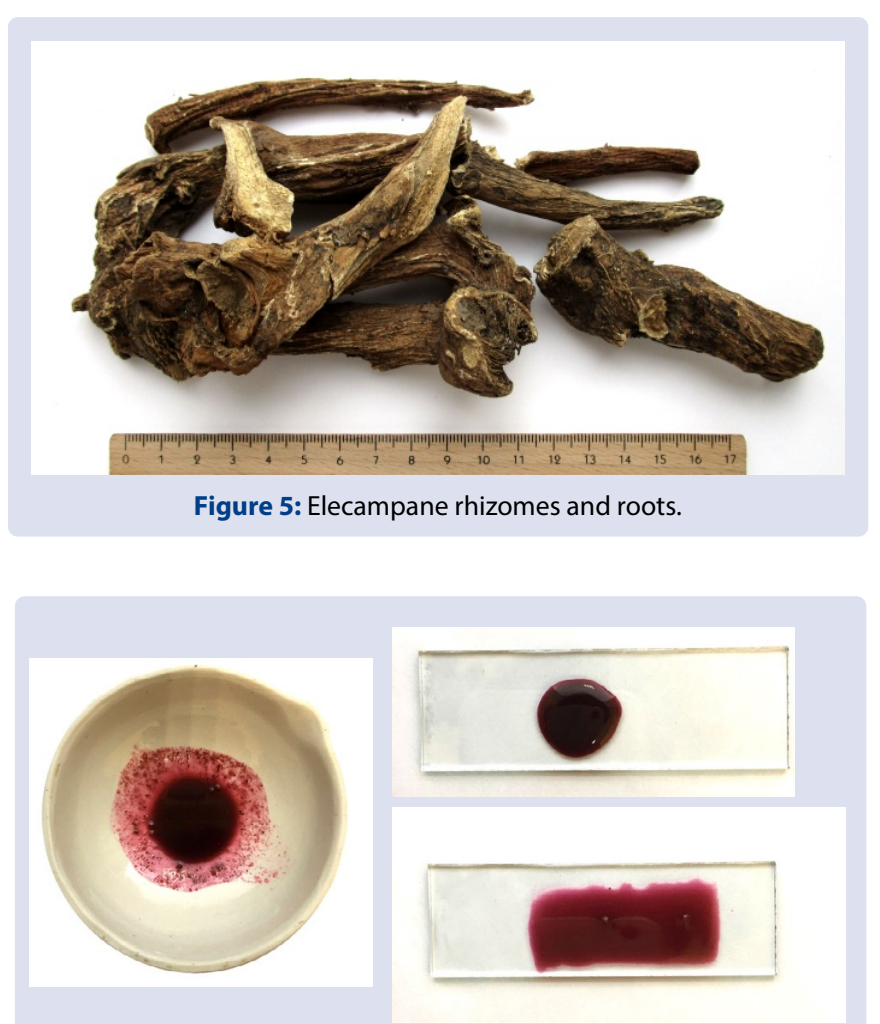

Figure 6: Qualitative reaction for inulin-containing MPRM (powder). 
added to the first flask and $5 \mathrm{ml}$ of water to the second flask (reference solution A). Both flasks are heated in a water bath at a temperature of $80^{\circ} \mathrm{C}$ for 20 minutes, then cooled to room temperature. The contents of the flasks are quantitatively transferred to the $25 \mathrm{ml}$ volumetric flasks and the volume of the solutions in them is adjusted to the mark with $30 \%$ hydrochloric acid, mixed (solution B of the test solution, reference solution B). After 15 minutes, the optical density of solution $B$ is measured on a spectrophotometer at a wavelength of $483 \mathrm{~nm}$ in a cuvette with a $10 \mathrm{~mm}$ layer thickness in comparison to the reference solution B. The total content of fructosans and fructose in terms of inulin in absolutely dry MPRM (X) is calculated by the formula:

$$
X=\frac{A \cdot 200 \cdot 100 \cdot 25 \cdot 100}{A_{1 \mathrm{~cm}}^{1 \%} \cdot a \cdot 2 \cdot 5 \cdot(100-W)}=\frac{A \cdot 5000000}{A_{1 \mathrm{~cm}}^{1 \%} \cdot a \cdot(100-W)}
$$

where $\mathrm{A}$ - the optical density of solution B of the test solution; $A_{1 \mathrm{~cm}}^{1 \%}-$ specific absorption coefficient of the reaction products of the interaction of inulin with resorcinol in an acidic medium, equal to 498; $\alpha$ - sample mass of MPRM, g; $W$ - moisture content in MPRM, \%. ${ }^{15}$

Dandelion is a widespread weed; it is a perennial herbaceous weed, up to $50 \mathrm{~cm}$ high. The dandelion has a short rhizome and a fleshy, spindleshaped root. In official medicine, roots containing polysaccharides (inulin), bitter glycosides, triterpene compounds, and other BAC are used. According to PM "Dandelion roots - Taraxaci radices", MPRM is presented by collected in the autumn (August-September), peeled from the collet, washed from the ground and dried roots of the wild perennial herb of the dandelion (Taraxacum officinale Wigg.), Asteraceae family (Figure 7). A decoction of dandelion roots has a choleretic effect, increases appetite, enhances the secretion of gastric juice. . $5,16,29-33^{-1}$

The PM includes the section "Determination of the main groups of biologically active substances", where a qualitative reaction for inulin is presented. When applying the iodine solution to the root cortex or powder, there should be no blue color (absence of starch). A root scraping or powder should be colored in a purple-pink color (inulin) from the addition of $20 \%$ a-naphthol alcohol solution and concentrated sulfuric acid. ${ }^{15-34}$

\section{Determination of inulin in mixture herbal products (herbal teas)}

The determination of inulin was also carried out in the mixture herbal products (MHP). An example is a recipe for a new expectorant collection "Lorpoliphyt" MHP (species "Lorpoliphytum") which includes the aerial parts of medicinal plants. It contains plantain leaves, chamomile and calendula flowers, horsetail, yarrow, and Saint-John'swort herbs, elecampane rhizomes and roots. The authors established the optimal conditions for the extraction of the total content of fructosans and fructose in terms of inulin in MHP: MPRM finesse $-1 \mathrm{~mm}$, the

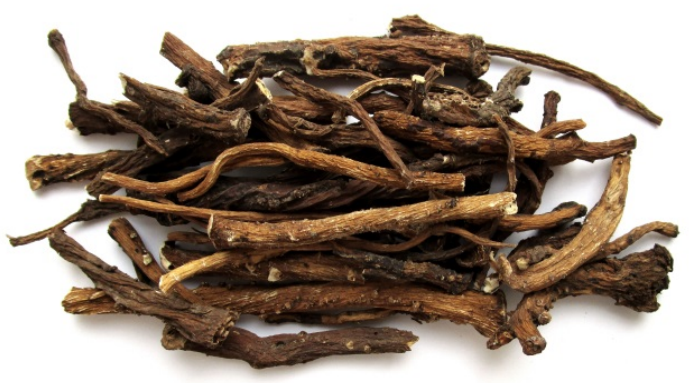

Figure 7: Dandelion roots. extractant - hot purified water, the ratio of raw material and extractant $-1: 50$, the extraction time -60 and 30 minutes in a boiling water bath with reflux condenser.

According to the procedure, MPRM analytical sample is crushed to the particle size passing through a $1 \mathrm{~mm}$ sieve. About $2.0 \mathrm{~g}$ (accurately weighed) of the crushed MHP is placed in a $100 \mathrm{ml}$ round bottom flask with a thin section, $60 \mathrm{ml}$ of water is added, heated in a boiling water bath for $1 \mathrm{~h}$ with the reflux condenser. Then it is cooled at room temperature for $5 \mathrm{~min}$; the resulting extract is filtered through cotton wool into a $100 \mathrm{ml}$ volumetric flask avoiding the ingress of MPRM on the cotton wool. The extraction is repeated with $30 \mathrm{ml}$ of water, heating for 30 minutes, then cooled at room temperature for 5 minutes and filtered through the same filter into the same flask. MPRM and filter are washed with $5 \mathrm{ml}$ of water; the cotton wool with raw materials is squeezed. To the resulting extract, $2 \mathrm{ml}$ of a $10 \%$ lead acetate solution is added in a $100 \mathrm{ml}$ flask; the solution is mixed and left for 10 minutes. Then $4 \mathrm{ml}$ of $5 \%$ sodium phosphate solution is added, mixed, left for 5 minutes. The volume of the solution in the flask is adjusted to the mark with water and mixed. It is filtered through a paper filter, discarding the first $10-15 \mathrm{ml}$ of the filtrate. $5 \mathrm{ml}$ of the subsequent filtrate is placed in a $100 \mathrm{ml}$ volumetric flask, the volume of the solution is adjusted to the mark with water and stirred (solution A).

In 2 conical $50 \mathrm{ml}$ flasks, $5 \mathrm{ml}$ of a $0.1 \%$ resorcinol alcohol solution and $10 \mathrm{ml}$ of $30 \%$ hydrochloric acid solution are added. $5 \mathrm{ml}$ of solution A (test solution) is added to the first flask, $5 \mathrm{ml}$ of water (reference solution) - to the second. Both flasks are heated in a water bath at a temperature of $80{ }^{\circ} \mathrm{C}$ for 20 minutes, cooled to room temperature. The contents of the flasks are quantitatively transferred to $25 \mathrm{ml}$ volumetric flasks. The volumes of the solutions in the flasks are adjusted to a mark with a $30 \%$ hydrochloric acid solution, and mixed. The optical density of the test solution is measured using a spectrophotometer at a wavelength of 483 $\mathrm{nm}$ (Figure 8) in a cuvette with a $10 \mathrm{~mm}$ layer thickness in comparison to the reference solution. The total content of fructosans and fructose (X) in terms of inulin and absolutely dry MPRM is calculated by the formula:

$$
X=\frac{A \cdot 100 \cdot 100 \cdot 25 \cdot 100}{498 \cdot m \cdot 5 \cdot 5 \cdot(100-W)}=\frac{A \cdot 1000000}{498 \cdot m \cdot(100-W)}
$$

where A - optical density of the analyzed solution; 498 - specific absorption coefficient of the reaction products of inulin with resorcinol in an acidic media; $m$ - mass of a MPRM sample, g; $W$ - moisture content in MPRM, \%.

The total content of fructosans and fructose in the collection samples ranged from 3.63 to $4.13 \%{ }^{34}$

\section{Determination of indicator for the BAC content in MPRM}

What is interesting is that there is no single terminology and methodology in the pharmacopoeial monographs of the State Pharmacopoeia of the Russian Federation. Two methods are completely identical (there are differences) in their presentation, but there are various terms for this indicator: "total content of fructosans and fructose in terms of inulin" and "total polysaccharides content in terms of fructose". The spectrophotometric method is rather nonspecific, to a greater extent it is not an absolute, but a relative indicator. The total content of PSh in terms of inulin and the content of the inulin substance itself are significantly different. Nevertheless, it is not possible to refuse this procedures in pharmacopoeial analysis at this stage of development of science and technology due to the low availability of instrumentation for control and analytical laboratories in the Russian Federation. It is necessary to determine what is sufficient for standardization purposes, the total content of all carbohydrates or the inulin content. It should be mentioned that low molecular weight compounds can be removed by 

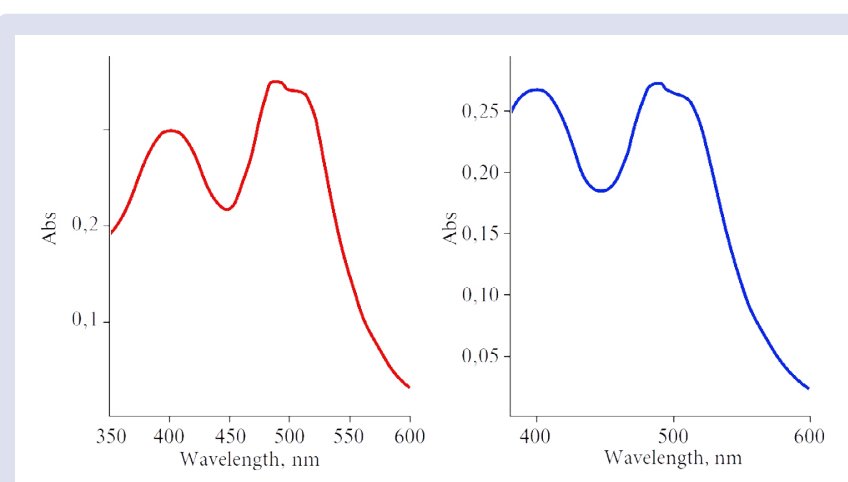

Figure 8: Absorption spectra of the reaction products of inulin with resorcinol in an acidic medium: $a$ - standard sample of inulin; $b$ - extract from the "Lorpolifit" herbal tea.

purification with high concentration alcohols (ethanol 90-95\%).

Based on the foregoing, it seems appropriate to unify the procedures for the quantitative determination of polysaccharides (polyfructans). It is necessary to suggest several methods for their determination: one is spectrophotometric, the other is HPLC-RID (or similar). In the monograph on inulin-containing MPRM, it is recommended to include two quantitative determinations on polysaccharides (inulin) and the target group of BAC (essential oil, bitter glycosides, etc.).

\section{Development of modern spectrophotometric methods for the analysis of inulin in MPRM}

It is important to note that the MPRM of inulin-containing plants includes other resorcinol-positive components: fructose, sucrose and several oligosaccharides, which can interfere with the PSh determination. To eliminate this drawback, the authors proposed a preliminary extraction of the raw material with $95 \%$ ethyl alcohol, in which high molecular weight fructans are insoluble. For a quantitative analysis of official MPRM - burdock roots, a spectrophotometric method for determining the content of Pfrus using a modified resorcinol method for determining ketoses is proposed. The metrological analysis of the procedure showed that it is reproducible and has a linearly varying error with a value of no more than $2 \%$ in the field of working concentrations. ${ }^{35}$

Similar experiments were carried out for the roots of burdock and elecampane. The optimal parameters for sample preparation of burdockroots are established. Preliminary extraction with $95 \%$ ethyl alcohol is carried out three times at $100^{\circ} \mathrm{C}$, the target extraction is carried out with water, the finesse degree of MPRM is $0.5-1.0 \mathrm{~mm}$. The procedure of quantitative determination of the total content of Pfrus in terms of fructose in the burdock roots is as follows. An MPRM analytical sample is crushed to the size of the particles passing through a $1 \mathrm{~mm}$ sieve. A portion of the MPRM is extracted with $95 \%$ ethyl alcohol in a boiling water bath for 60 minutes. After cooling, the extract is filtered. The extraction of MPRM is repeated under the same conditions 2 more times. Water is added to the purified MPRM and heated in a boiling water bath for 60 minutes. The extraction of MPRM is repeated under the same conditions 2 more times. A $0.01 \%$ thiourea solution, $1 \%$ resorcinol solution, $95 \%$ ethyl alcohol, concentrated hydrochloric acid are added to an aliquot of the obtained extraction and heated in a boiling water bath. The mixture is cooled, diluted, the optical density of the solution is determined at a wavelength of $480 \mathrm{~nm}$; the total content of polyfructans in terms of fructose in absolutely dry MPRM is calculated by the same principle as described above.

For elecampane MPRM, the optimal conditions for the analytical reaction were also selected; studies were carried out for optimization of the reaction mixture composition. It should include $15 \%$ hydrochloric acid, $52 \%$ ethanol to achieve maximum optical density. The addition of thiourea slows down the process of destruction of the analytical component. Inulin has partial solubility in aqueous solutions of ethanol of various concentrations; $50 \%$ solubility is already observed for 61 $65 \%$ ethanol solutions. Therefore, for MPRM preparation, it is correct to use only $95 \%$ extractant solutions, which, with 3-fold extraction, can almost completely remove low molecular weight carbohydrates. ${ }^{36}$

\section{CONCLUSION}

Preparations obtained from inulin-containing plants have a very diverse effect on the human body. Inulin is an integral part of water extracts obtained from the raw materials of dandelion, elecampane, burdock, which are pharmacopeia plants in the Russian Federation and other countries. It is impossible to overestimate the relevance of expanding research on inulin taking into account all the areas of this polyfructosan application in modern medicine and pharmacy. In this regard, it seems appropriate to justify the possibility of medical use of these plants MPRM as sources of inulin-containing biologically active complexes. Inulin is a pharmacologically active component of the raw material and can expand the indications for the use of dandelion, burdock and elecampane preparations. This also directly relates to quantification methods. Unfortunately, pharmacopoeial analysis of raw materials containing inulin does not fully satisfy all the contemporary requirements for herbal drugs quality control. This means that the development of new or improvement of existing methods remains an urgent task of modern medicine and pharmacy in the Russian Federation.

\section{ACKNOWLEDGMENT}

This paper was financially supported by "Russian Academic Excellence Project 5-100" (Sechenov University). The publication has been prepared with the support of the "RUDN University Programm 5-100".

\section{CONFLICTS OF INTEREST}

None.

\section{REFERENCES}

1. Mills S, Bone K. Principles and practice of phytotherapy. Modern herbal medicine. Churchill Livingstone, 2000

2. Souza CA, Andrade WM, Ramos TS, Filho AJ, Freitas AL, Lima TC, et al Medicinal Plants in Basic Care: A Study of Clinical Practice. Pharmacognosy Journal. 2019;11(4):796-802.

3. Ananina NA, Andreeva OA, Mycots LP, Oganesyan ET. Standardization of inulin extracted from Dahlia single tubers and some physicochemical properties of inulin. Pharmaceutical Chemistry Journal. 2009;43(3):157-9.

4. Shoaib M, Shehzad A, Omar M, Rakha A, Raza H, Sharif HR, et al. Inulin Properties, health benefits and food applications. Carbohydrate polymers 2016;147:444-54

5. Apolinário AC, de Lima Damasceno BP G, de Macêdo Beltrão NE, Pessoa A Converti $A$, da Silva JA. Inulin-type fructans: A review on different aspects of biochemical and pharmaceutical technology. Carbohydrate polymers. 2014;101:368-78.

6. Wang $H$, Zhang Z, Liang L, Wen S, Liu C, Xu X. A comparative study of high-performance liquid chromatography and colorimetric method for inulin determination. European Food Research and Technology. 2010;230(5):701-6.

7. Petkova N, Denev P. Methods for determination of inulin. In Monograph of $4 \mathrm{rd}$ European young engineers conference (Vol. 135). 2015

8. Bokov DO, Khromchenkova EP, Sokurenko MS, Vasilev AV, Bessonov WV Development of a technique for the determination of inulin in natural instant chicory after enzymatic hydrolysis by high-performance liquid chromatography. Voprosy pitaniia. 2017;86(5):50-5.

9. Barclay T, Ginic-Markovic M, Cooper P, Petrovsky N. Inulin - a versatile polysaccharide with multiple pharmaceutical and food chemical uses. J Excip Food Chem. 2010;1(3):27-50.

10. Yevtifieieva OA, Proskurina KI, Smelova NN, Petukhova IY. Development and validation of UV-Spectrophotometric method for quantitative determination of inulin by specific absorbance. Der Pharma Chemica. 2016;8(1):213-22. 
11. Rane R, Shelar R, ShindeY, Lad S, Desai S, Vartak M, et al. Spectrophotometric Method for Quantitative Determination of Inulin in Naturolax - A Powder. Int J Pharma Res Health Sci. 2018;6(1):2160-4.

12. Li J, Hu D, Zong W, Lv G, Zhao J, Li S. Determination of inulin-type fructooligosaccharides in edible plants by high-performance liquid chromatography with charged aerosol detector. J Agric Food Chem. 2014;62(31):7707-13.

13. USP Pharmacopoeia [Official site]. Inulin. URL: https://www.usp.org/

14. Sánchez-Viesca F, Gómez R. Reactivities involved in the Seliwanoff reaction. Modern Chemistry. 2018;6(1):1-5

15. State Pharmacopoeia of Russian Federation, XIV ed., Vol. IV. Federal electronic medical library. The Russian Federation Ministry of Health [Official site]. URL: http://femb.ru/femb/pharmacopea.php Accessed date 08.01.2019 [in Russian].

16. Drug Guide RLS® https://www.rlsnet.ru/Accessed date 08.01.2019 [in Russian].

17. Milani E, Koocheki A, Golimovahhed QA. Extraction of inulin from Burdock root (Arctium lappa) using high intensity ultrasound. Int J Food Sci Tech. 2011;46(8):1699-704.

18. Shmatkov DA, Belyakov KV, Popov DM. Determination of inulin in the roots of burdock. Pharmacy. 1998;6:17-20.

19. Azizov UM, Khadzhieva UA, Rakhimov DA, Mezhlumyan LG, Salikhov SA Chemical composition of dry extract of Arctium lappa roots. Chem Nat Compd. 2012;47(6):1038-9.

20. Kardošová A, Ebringerová A, Alföldi J, Nosál'ová G, Fraňová S, Hřı खbalová V. A biologically active fructan from the roots of Arctium lappa L., var. Herkules. Int J Biol Macromol. 2003;33(1-3):135-40.

21. Chan YS, Cheng LN, Wu JH, Chan E, Kwan YW, Lee SMY, et al. A review of the pharmacological effects of Arctium lappa (burdock). Inflammopharmacology. $2011 ; 19(5): 245-54$

22. Krantz Jr JC, Carr CJ. A physiochemical study of the carbohydrate occurring in the root of Arctium lappa. ¡ Phys Chem. 2002;35(3):756-63.

23. Fu Y L. Isolation, purification, and structural elucidation of a fructan from Arctium lappa L. J Med Plant Res. 2009;3(3):171-3.

24. Petkova N, Ognyanov M, Todorova M, Denev P. Ultrasound-assisted extraction and characterisation of inulin-type fructan from roots of elecampane (Inula helenium L.). Acta Scientifica Naturalis. 2015;1(1):225-35.
25. Petkova N, Vrancheva R, Mihaylova D, Ivanov I, Pavlov A, Denev P. Antioxidant activity and fructan content in root extracts from elecampane (Inula helenium L.). J BioSci Biotechnol. 2015;4(1):101-7.

26. Afemei M, Gille E, Boz I, Toma C, Zamfirache MM. Aspects regarding the qualitative and quantitative phytochemical analysis of the Inula helenium L. species. Analele Stiintifice ale Universitatii" Al. I. Cuza" din lasi. 2012;58(1):29-34

27. Mitrofanova IY, Yanitskaya, AV. Assay of the total content and dynamics of the accumulation of polyfructans in the rhizomes and roots of the elecampane (Inula helenium L.) grown in the Volgograd Region. Pharmaceutical Chemistry Journal. 2013;47(3):169-71.

28. Singh P, Sharma BM. Pharmacognostic study of root of Inula racemosa Hook Q J Crude Drug Res. 1972;12(3):1929-36.

29. Rutherford PP, Deacon AC. The mode of action of dandelion rootfructofuranosidases on inulin. Biochemical Journal. 1972;129(2):511-2.

30. Schütz K, Muks E, Carle R, Schieber A. Separation and quantification of inulin in selected artichoke (Cynara scolymus L.) cultivars and dandelion (Taraxacum officinale Web. ex Wigg.) roots by high-performance anion exchange chromatography with pulsed amperometric detection. Biomedical Chromatography. 2006;20(12):1295-303.

31. Grela ER, Sobolewska S, Roziński T. Effect of inulin extracts or inulin-containing plant supplement on blood lipid indices and fatty acid profile in fattener tissues. Polish journal of veterinary sciences. 2014;17(1):93-8

32. Petkova N, Ivanov I, Topchieva S, Denev P, Pavlov A. Biologically active substances and in vitro antioxidant activity of different extracts from Dandelion (Taraxacum officinale) roots. Sci Bull Ser F Biotechnol. 2015;19:190-7.

33. Trojanova I, Rada $V$, Kokoška L, Vlkova E. The bifidogenic effect of Taraxacum officinale root. Fitoterapia. 2004;75(7-8):760-3.

34. Bukhanova UN, Popov DM, Selezenev NG. Procedure for determination of the sum of fructosans and fructose in the Lorpolifit herbal tea. Pharmacy. 2013;1:22-4

35. Olennikov DN, Tankhaeva LM. Study of the colorimetric reaction of inulin with resorcinol, depending on the conditions of its implementation. Khimija Rastitel'nogo Syr'ja. 2008;1:87-93.

36. Olennikov DN, Tankhaev LM. A quantitative assay for total fructans in burdock (Arctium spp.) roots. Russ J Bioorg Chem. 2011;37(7):893-8.

\section{GRAPHICAL ABSTRACT}

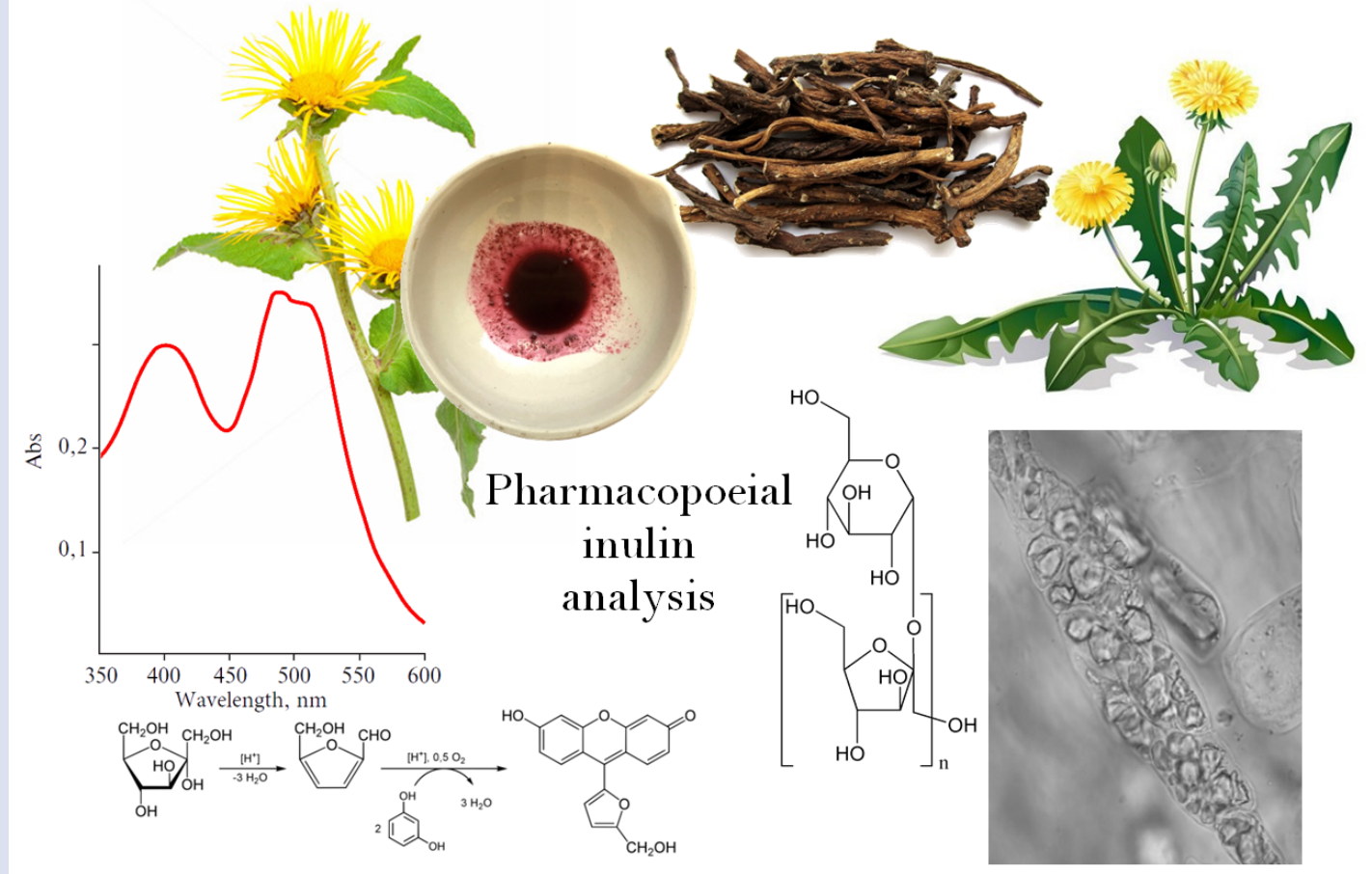




\section{ABOUT AUTHORS}

- Bokov Dmitry Olegovich: Candidate of Pharmaceutical Sciences (Ph.D.), Institute of Pharmacy, Sechenov University; Laboratory of Food Chemistry, Federal Research Center of Nutrition, Biotechnology and Food Safety.

- Karabeshkin Dmitry Ivanovich: Student, Normal physiology department, Northern State Medical University.

- Samylina Irina Alexandrovna: Corresponding member of Russian Academy of Sciences, Doctor of Pharmaceutical Sciences, Professor, Professor, Institute of Pharmacy, Sechenov University.

- Potanina Olga Georgievna: Doctor of Pharmaceutical Sciences, Head of the Pharmaceutical chemistry and Pharmacognosy Chair, Director of the Research and Development Department of the Shared Research and Education Center of the Peoples' friendship university of Russia (RUDN University).

- Krasnyuk Ivan Ivanovich (junior): Doctor of Pharmaceutical Sciences, Professor, Head of Department of Analytical, Physical and Colloid Chemistry, Institute of Pharmacy, Sechenov University.

- Malinkin Alexey Dmitrievich: Candidate of Pharmaceutical Sciences (Ph.D.), Research fellow, Laboratory of Food Chemistry, Federal Research Center of Nutrition, Biotechnology and Food Safety.

- Sergunova Ekaterina Vyacheslavovna: Doctor of Pharmaceutical Sciences, Associate Professor, Professor, Institute of Pharmacy, Sechenov University.

- Kovaleva Tatyana Yurievna: Candidate of Pharmaceutical Sciences (Ph.D.), Associate Professor, Institute of Pharmacy, Sechenov University.

- Bobkova Natalya Vladimirovna: Doctor of Pharmaceutical Sciences, Associate Professor, Professor, Institute of Pharmacy, Sechenov University.

- Antsyshkina Alla Mikhailovna: Candidate of Pharmaceutical Sciences (Ph.D.), Associate Professor, Institute of Pharmacy, Sechenov University.

- Bondar Alina Aleksandrovna: Candidate of Pharmaceutical Sciences (Ph.D.), Associate Professor, Institute of Pharmacy, Sechenov University.

- Evgrafov Alexander Alexandrovich: Candidate of Pharmaceutical Sciences (Ph.D.), Associate Professor, Institute of Pharmacy, Sechenov University.

- Galiakhmetova Elvira Khalitovna: Candidate of Pharmaceutical Sciences (Ph.D.), Associate Professor of the Department of Pharmacognosy with a course in botany and the basics of herbal medicine, Bashkir state medical University.

- Moiseev DmitryVladimirovich: Doctor of Pharmaceutical Sciences, Associate Professor, Head of the Chair of Standardization of Medicines, Vitebsk State Medical University.

- Bessonov Vladimir Vladimirovich: Doctor of Biological Sciences, Head of Laboratory of Food Chemistry, Federal Research Center of Nutrition, Biotechnology and Food Safety.

Cite this article: Bokov DO, Karabeshkin DI, Samylina IA, Potanina OG, Krasnyuk II, Malinkin AD, et al. Pharmacopoeial Analysis of Inulin-Containing Medicinal Plant Raw Materials and Drugs. Pharmacog J. 2020;12(2):415-21. 